\title{
Preparation, Characterization and Thermal Properties of Paraffin Wax - Expanded Perlite Form-Stable Composites for Latent Heat Storage
}

\author{
Tugba GURMEN OZCELIK*
}

Ege University, Faculty of Engineering, Chemical Engineering Department 35100 Bornova-Izmir, Turkey

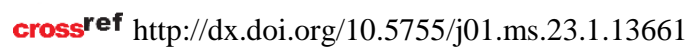

\author{
Received 18 November 2015; accepted 15 May 2016
}

\begin{abstract}
In this study, form-stable composite phase change materials (PCM) for latent heat storage were prepared by impregnating paraffin wax into the pores of the expanded perlite (EP). The characterization of the composite PCMs was performed by FTIR, TGA, SEM and DSC analysis. The melting point and heat of fusion were determined for $25 \%$ paraffin included composite, as $54.3{ }^{\circ} \mathrm{C}$ and $94.71 \mathrm{~J} / \mathrm{g}$ and for $45 \%$ paraffin included composite as $53.6{ }^{\circ} \mathrm{C}$ and $106.69 \mathrm{~J} / \mathrm{g}$, respectively. The FTIR results showed that there was no chemical reaction between the perlite and paraffin. TGA analysis indicated that both composite PCMs had good thermal stability. SEM images showed that the paraffin was dispersed uniformly into the pores and on the EP surface. There was no leakage and degradation at the composite PCMs after heating and cooling cycles. According to the results, both prepared composites showed good thermal energy storage properties, reliability and stability. All results suggested that the presented form- stable composite PCMs has great potential for thermal energy storage applications.

Keywords: form-stable composite, PCM, expanded perlite, paraffin, heat storage materials.
\end{abstract}

\section{INRODUCTION}

The energy consumption has increased with use of energy intensive applications and development of the technology. On the other hand, the used energy resources of the earth are being depleted rapidly. Energy storage is as important as to develop renewable energy sources.

Thermal energy storage systems are used in many thermal applications such as heating and cooling systems, solar energy collectors, air-conditioning in buildings, and industrial heat recovery systems $[1,2]$. Thermal energy storage can be stored sensible heat, latent heat and thermochemical or combination of these.

Phase change materials (PCM) are one of the most used materials in thermal energy storage and temperature control of many engineering applications [1, 3-8]. PCMs store energy by absorbing and releasing of heat in phase change processing in the form of the latent heat of fusion. Depending on their phase change states, PCMs are classified in four categories liquid-gas, solid-liquid, solid-gas and solid-solid PCMs [2 - 4]. Although solid-gas and liquid-gas phase changes provided higher latent heat, the volume changes in the phase transition is excessive and this change in volume makes the system complicated and impractical [3]. Therefore, many researchers are concerned with the solid-liquid and solid-solid phase transformations. The solid liquid PCMs are classified in three main groups: Organic, inorganic and eutectic. Organic PCMs can be paraffin or non-paraffin. The latent heat of inorganic PCMs are greater than that of organic PCMs but during the phase change of inorganic PCMs, sub cooling and phase separation may occur. On the other hand, the organic PCMs have many advantages: non corrosive, no sub cooling, non-toxic, and have a steady performance [3, 9-12].
Due to their desirable properties such as high latent heat, negligible subcooling, being chemically inert and stable, and commercial availability, paraffin is widely used as a latent heat storage material. However, paraffin suffers liquid leakage during the solid-liquid phase change $[3-6,13]$. It is necessary to develop new methods to prevent the leakage during process and to improve applicability of paraffin as PCM. Many researchers used support materials such as graphite, aluminium powder, expanded graphite, expanded perlite, carbon nanotubes, and activated carbon to avoid the liquid leakage [14-18].

Expanded perlite (EP) is a glassy volcanic rock, and through its porous structure, high specific surface area, low density, low cost, and good thermal reliability it is one of the promising porous carriers for PCMs. Li et al. [14] prepared shape-stabilized PCMs by adsorbing paraffin into the pores of EP by the vacuum adsorption method and gypsum was added to the prepared PCMs for use as heat storage boards in buildings. Karaipekli et al. [19] prepared an eutectic mixture of capric acid and myristic acid to absorb it into the EP for latent heat storage in buildings. Z. Lu et al. [20] prepared form stable PCMs by using the direct impregnation method. The paraffin was impregnated into the EP pores and according to their results, there was no leakage. Zhao et al. [21] developed form stable PCMs with paraffin wax and halloysite composite and they added the graphite or carbon nanotubes to prevent the form of the composite at high temperature.

In the present study, form stable paraffin wax/expanded perlite composites with two different paraffin mass fractions ( $25 \%$ and $45 \%$ paraffin included by weight) were prepared by the wet impregnation method. This simplest method is cheapest and environmentally safe method to prepare composite PCM. The commercial paraffin was absorbed

\footnotetext{
* Corresponding author. Tel.: +90-232-3111486.

E-mail address: t.gurmen.ozcelik@ege.edu.tr (T.G.Ozcelik)
} 
into the porous structure of the expanded perlite by using ethyl alcohol as carrier solvent. Paraffin was enclosed into the EP pores and during the phase change process the leakage of the paraffin was prevented. The thermal properties and stability of composite PCMs were analyzed by differential scanning calorimeter (DSC) and by a thermo gravimetric analysis instrument (TGA). The structures and morphologies of the perlite and paraffin/EP composites were analyzed with the Fourier transformation infrared spectroscope (FTIR) and scanning electronic microscope (SEM). Their heat accumulation and heat release properties were determined with heating and cooling processes. Finally, the thermal reliability of the prepared composite PCMs was investigated with a heating and cooling cycling test.

\section{EXPERIMENTAL}

\subsection{Materials}

Paraffin wax was used as a PCM (product code is U391) and was supplied by Oztin Chemical Company, Turkey. The melting point and latent heat of the paraffin wax are $52.8^{\circ} \mathrm{C}$ and $180 \mathrm{~J} / \mathrm{g}$, respectively. Expanded Perlite (EP) was used as a support material and it was obtained from the Batıcim-AS Company, Turkey. In the preparation of the composites, ethyl alcohol (> 99.5) from Merck was used as carrier solvent. The Brunauer, Emmet and Teller (BET) surface area of the used EP was $2.3 \mathrm{~m}^{2} / \mathrm{g}$.

\subsection{Preparation of paraffin/expanded perlite composite PCMs}

Two different mass fraction of paraffin and EP form stable PCMs were prepared using a wet impregnation method. Initially 25:75 and 45:55 mass ratio of paraffin and EP were weighted with $0.001 \mathrm{~g}$ accuracy. The paraffin wax was heated above its melting point, and absolute ethyl alcohol was added to the paraffin wax with $3: 1$ mass ratio (ethyl alcohol/ paraffin) and stirred vigorously at $60{ }^{\circ} \mathrm{C}$, until homogeneity was maintained. Then the EP was added to the paraffin wax- ethyl alcohol solution and the resulting mixture was placed in an ultrasonic bath at $60{ }^{\circ} \mathrm{C}$ for 1 hour to diffuse the solution into the pores of the EP. After this, the mixture was stirred at $60{ }^{\circ} \mathrm{C}$ for 2 hours to evaporate the ethyl alcohol. Finally, the composite mixture was put into an oven at $80{ }^{\circ} \mathrm{C}$ for 16 hours to remove all the ethyl alcohol solvent.

The prepared form stable PCMs were included $25 \%$ paraffin wax and $45 \%$ paraffin wax by weight.

\subsection{Characterization of the prepared composite PCMs}

The structural analysis of the prepared composite PCMs, perlite, and paraffin were recorded using the FT-IR (Perkin Elmer Spectrum 100) from $400-4000 \mathrm{~cm}^{-1}$ with a resolution of $2 \mathrm{~cm}^{-1}$ with a $\mathrm{KBr}$ pellet. The surface morphology of the composite PCMs were expressed with a scanning electronic microscope (FEI Quanta 250 FEG SEM). The thermal stability of the PCMs was determined by thermo gravimetric analysis instrument (Perkin Elmer Diamond TG/DTA). Temperature programs were run from 30 to $500{ }^{\circ} \mathrm{C}$ at a heating rate of $10^{\circ} \mathrm{C} / \mathrm{min}$ in a nitrogen atmosphere. The thermal properties of the form stable composites PCMs, such as melting and freezing temperatures, and latent heats were measured by a differential scanning calorimeter instrument (DSC, PerkinElmer Diamond). The heating and cooling rate of $5^{\circ} \mathrm{C} / \mathrm{min}$ was performed under a constant nitrogen stream at a flow rate of $10 \mathrm{ml} / \mathrm{min}$ for all the DSC measurements. The heat accumulation and heat release properties of the paraffin wax, perlite and prepared PCM composites were determined using heating and cooling processes. In heating and cooling cycles, a certain amount of sample was put into a tube and thermocouple was placed in the middle of the sample. The sample was placed in the hot water bath at $70{ }^{\circ} \mathrm{C}$ for heating. When the tube temperature was reached equilibrium the sample tube was transferred into cryostat at $-5^{\circ} \mathrm{C}$ for cooling. During the heating and cooling of the sample, the temperature of tube was recorded with time. The heating cooling cycles were repeated 100 times to determine the stability of the PCMs.

\section{RESULTS AND DISCUSSION}

\subsection{FT-IR analysis}

The FTIR spectra of perlite, paraffin wax, and prepared paraffin wax/EP composites are shown in Fig. 1. In the FTIR spectra of paraffin wax, the symmetrical stretching vibration of its $\mathrm{CH}_{3}$ group is presented at $2915 \mathrm{~cm}^{-1}$, and the symmetrical stretching vibration of its $\mathrm{CH}_{2}$ group is shown at $2849 \mathrm{~cm}^{-1}$. The peak at $1471 \mathrm{~cm}^{-1}$ is due to the deformation vibration of its $\mathrm{CH}_{2}$ and $\mathrm{CH}_{3}$. The peak at $740 \mathrm{~cm}^{-1}$ corresponds to out-of-plane blending vibration of $\mathrm{C}-\mathrm{H}$ group [22]. In the FTIR spectra of the expanded perlite, the peak at $1020 \mathrm{~cm}^{-1}$ represents the $\mathrm{SiO}-\mathrm{Si}$ stretching vibrations. The adsorption at $850-900 \mathrm{~cm}^{-1}$ corresponds to the vibrational modes of the $\mathrm{Al}-\mathrm{OH}-\mathrm{Al}$ and $\mathrm{AlOH}-\mathrm{Mg}$ groups, respectively. The peak at $786 \mathrm{~cm}^{-1}$ represents the $\mathrm{Si}$ $\mathrm{C}$ stretching and $\mathrm{CH}_{3}$ rocking vibration [23]. In the FTIR spectra of both the composites, only the expanded perlite and paraffin wax peaks were seen, new peaks were not observed. This indicates that there was no chemical interaction between the expanded perlite and paraffin wax. The FTIR results show that the paraffin wax and expanded perlite preserve their original form in the composites and the prepared composites are just a physical combination of the paraffin wax and expanded perlite.

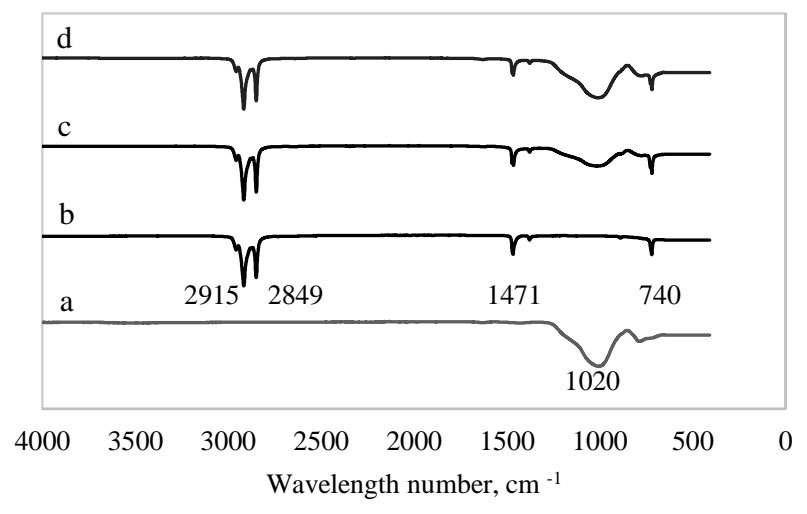

Fig. 1. FTIR Spectra: $a-$ perlite; b-paraffin wax; c-25 wt.\% paraffin wax; $d-45$ wt. $\%$ paraffin wax included composite 


\subsection{TGA analysis}

For the PCM composite, one of the most important factors is thermal stability. To determine the thermal stability of the composites, TGA is commonly used. In Fig. 2, the TGA curves of both the composites PCMs are shown. The weight loss of the paraffin wax starts nearly $135{ }^{\circ} \mathrm{C}$. Due to the evaporation of paraffin wax the decomposition amount increased rapidly after this temperature and $99 \%$ weight loss were measured at $280{ }^{\circ} \mathrm{C}$. Below the temperature at $155^{\circ} \mathrm{C}$, there was no decomposition for both prepared composites. The PCM composites are stable up to $155^{\circ} \mathrm{C}$. At $245^{\circ} \mathrm{C}, 5 \%$ decomposition is seen. The weight loss starting temperatures of composites were higher than that of paraffin wax. This indicates that the physical interaction between perlite and wax. Several researchers also reported these interactions $[15,19,20]$. Z. Liu et al [20], deal with expanded perlite can improve the thermal stability of composites and paraffin EP composites more stable than the paraffin. According to Fig. 2, when the weight losses of the composites are compared, the amount of weight losses above $400{ }^{\circ} \mathrm{C}$ are related to the amount of paraffin wax in the PCM composites. Therefore, we can say that, all paraffin wax in the PCM composites decomposes above $400{ }^{\circ} \mathrm{C}$.

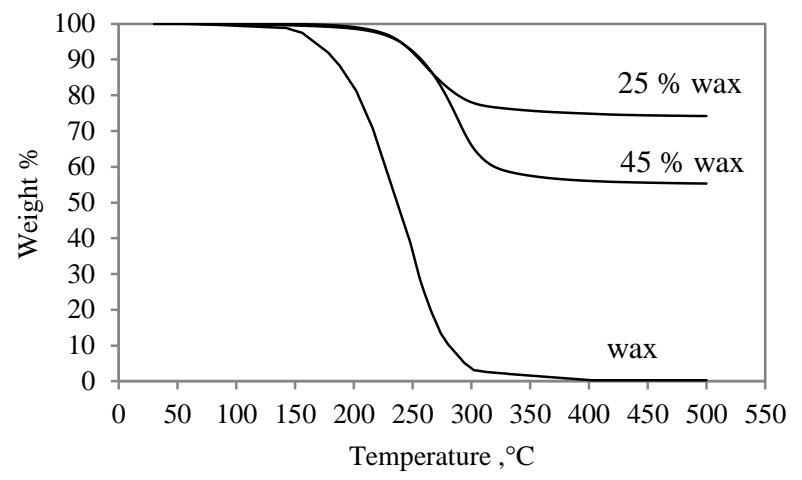

Fig. 2. TGA curves of paraffin wax, and 25 wt.\% paraffin wax and 45 wt. $\%$ paraffin wax included composites

\subsection{Thermal performance}

Heating and cooling processes were applied to the paraffin wax and prepared PCM composites. These results were plotted as temperature versus time graph which is shown in Fig. 3. The heating and cooling processes were applied for $20 \mathrm{~min}$ to observe the stable conditions. As it can be seen in Fig. 3, the paraffin wax has a higher heating and cooling rate than the prepared composites. Although the heating and cooling rate decreased with the perlite amount added to the composite, the difference was not remarkable. This means the thermal conductivity of the perlite is as low as the paraffin wax.

\subsection{SEM results}

In Fig. 4 the SEM images of the expanded perlite and prepared composite PCMs are shown. The porous structure of the perlite in Fig. $4 \mathrm{a}-\mathrm{c}$ shows that the paraffin wax was dispersed uniformly into the pores and on the perlite surface. After 100 heating and cooling cycles, the morphologies of the prepared composite PCMs were checked and the SEM images are given in Fig. $5 \mathrm{a}-\mathrm{c}$. When the structure of the composite PCMs before and after 100 heating and cooling cycle are compared, there are no changes in the morphology of the composites and there is no leakage and degradiation of the composite PCMs after the heating and cooling cycles. Perlite has a porous structure and its pores are suitable to keep the paraffin wax within.

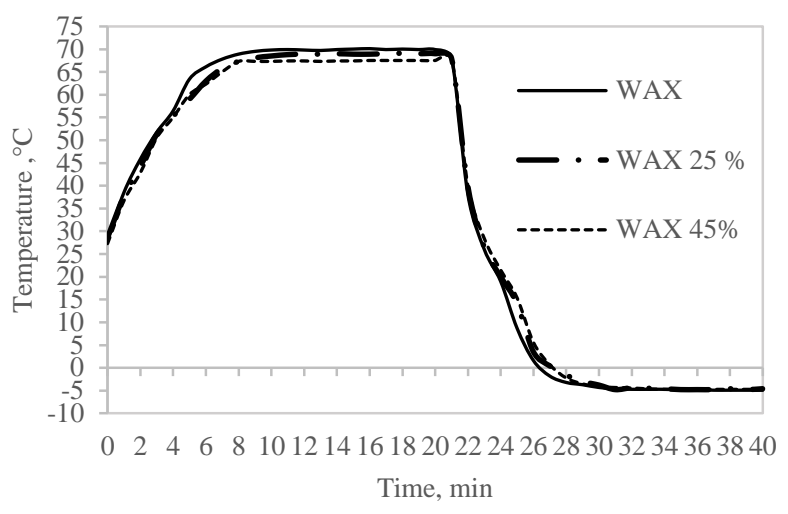

Fig. 3. Heating and cooling processes for paraffin wax, $25 \mathrm{wt} . \%$ and 45 wt. \% paraffin wax included composites

\subsection{DSC results}

The melting and freezing points and latent heats of the paraffin wax and prepared composite PCMs before and after 100 heating-cooling cycles are listed in Table 1 and the DSC curves are given in Fig. 6. According to the DSC curves, there exist two peaks. The minor peak represents the solidsolid phase change and the main peak corresponds to the solid-liquid phase change. The phase change temperatures of both the prepared composite PCMs increased approximately 1 to $1.5{ }^{\circ} \mathrm{C}$ compared with the phase change temperatures of the paraffin wax. The change of the melting temperature is a denotation of the strength of the interactions between the PCM and its support. If there is a strong interaction between the PCM and support pores, the melting temperature will increase and some researchers have found the same results for different composites [11, 18, 24]. According to the results, strong interaction is observed between the used paraffin wax and expanded perlite. Comparing the latent heat data of the paraffin wax with the prepared composite PCMs, the latent heat value decreases with the increasing EP amount into the composite PCMs. Including a $75 \%$ and $55 \%$ of perlite by weight in the composite PCM decreases the latent heat only, $47 \%$ and $40 \%$, respectively. This decrease can not only be related with the increasing amount of perlite in the composite PCM it also depends on the interaction between the expanded perlite and paraffin wax. C. Wang et al. have mentioned that the reason for the loss of latent heat is the interaction between the PCM and supporting material [11].

One of the important parameter for the composite PCM is the thermal reliability. The thermal properties of the materials can change after many thermal cycles and latent heat and phase change temperatures may deform significantly. A suitable composite PCM should have steady thermal properties with many phase change cycles without degradation [8-10]. According to the DSC results, the prepared composite PCMs retain their latent heat and phase change temperatures after 100 heating and cooling cycles. 


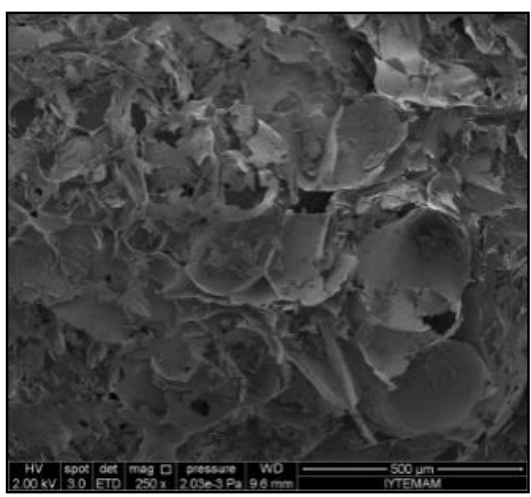

a

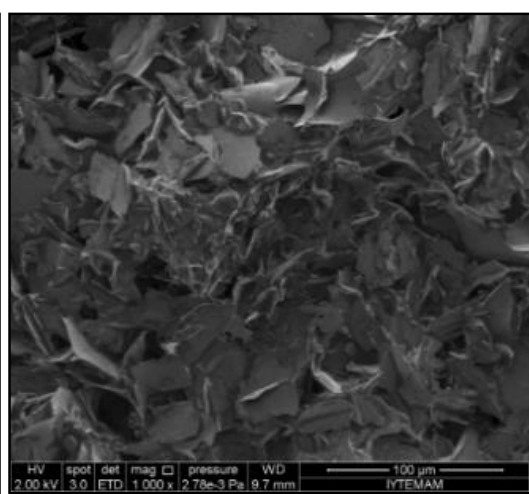

b

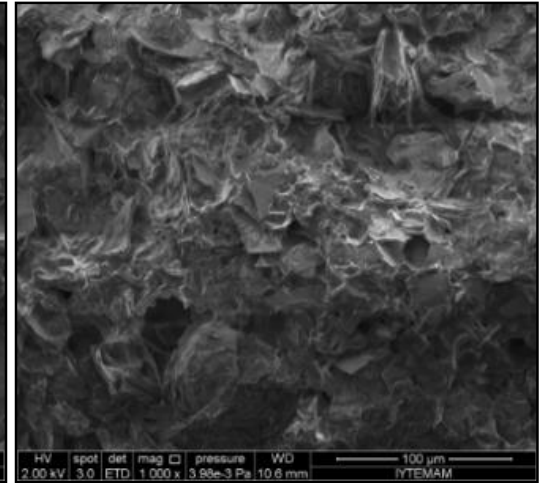

c

Fig. 4. SEM images: a-expanded perlite; $b-25$ wt. $\%$ wax included composite; $c-45$ wt. $\%$ wax included composite

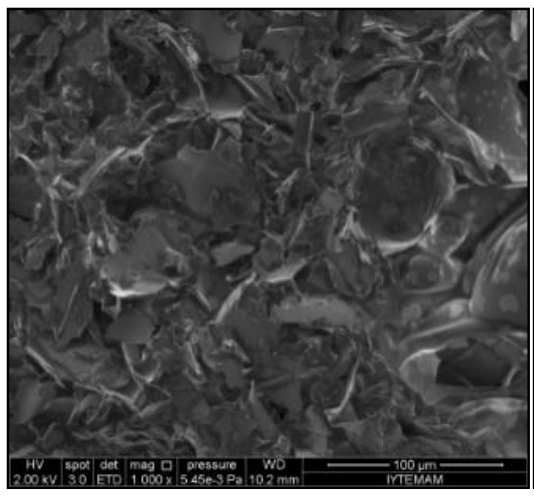

a

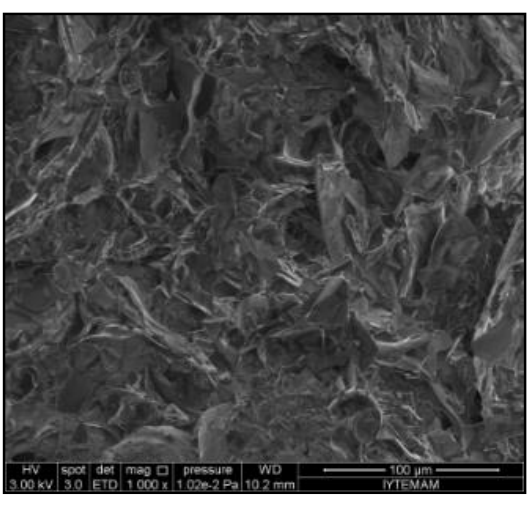

$\mathrm{b}$

Fig. 5. SEM images of after 100 heating-cooling cycles: $a-$ of 25 wt. $\%$ aged wax included composite; $b-45$ wt. $\%$ aged wax included composite

Table 1. Thermal properties of the composite PCMs

\begin{tabular}{|l|c|c|c|c|}
\hline & Melting point, ${ }^{\circ} \mathrm{C}$ & Melting latent heat, $\mathrm{J} / \mathrm{g}$ & Freezing point, ${ }^{\circ} \mathrm{C}$ & Freezing latent heat, $\mathrm{J} / \mathrm{g}$ \\
\hline Paraffin Wax & 52.8 & 180.02 & 52.5 & -178.01 \\
\hline $25 \mathrm{wt} \%$ wax included composite PCM & 54.3 & 94.71 & 54.2 & -93.50 \\
\hline $45 \mathrm{wt} \%$ wax included composite PCM & 53.6 & 106.69 & 53.7 & -99.66 \\
\hline $\begin{array}{l}25 \mathrm{wt} \% \text { wax included composite PCM } \\
\text { After heating-cooling }\end{array}$ & 53.9 & 92.56 & 53.3 & -92.20 \\
\hline $\begin{array}{l}45 \mathrm{wt} \% \text { wax included composite PCM } \\
\text { After heating-cooling }\end{array}$ & 53.5 & 105.77 & 53.4 & -98.91 \\
\hline
\end{tabular}

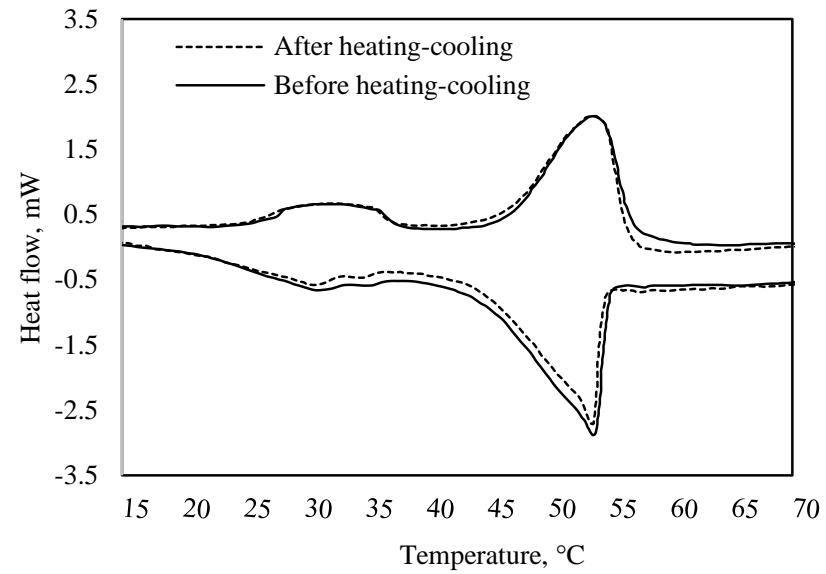

a

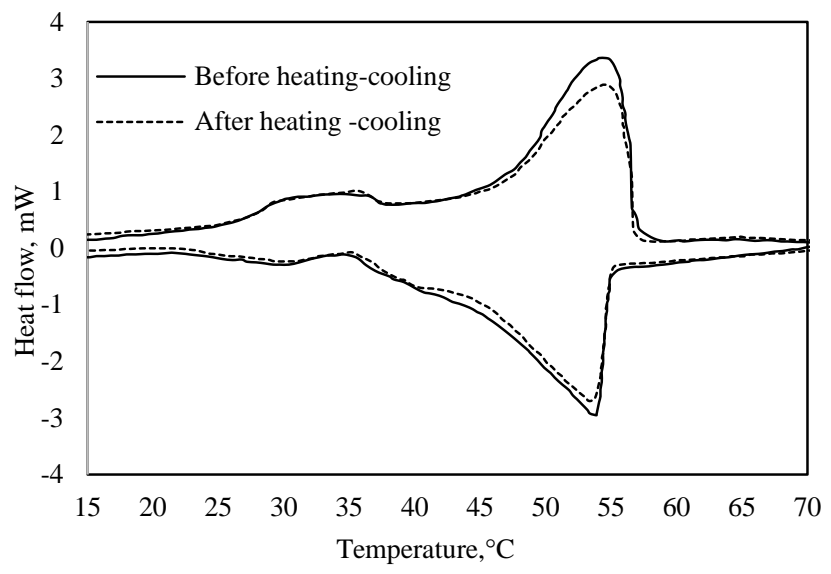

b

Fig. 6. DSC curves: $a-25 \%$ wax included composite PCM; b-45 \% wax included composite PCM 


\section{CONCLUSIONS}

Paraffin/EP composite PCMs were prepared with one of the easiest and cheapest methods of wet impregnation. Paraffin was absorbed into the pores of the EP using an ultrasonic bath. The used method and materials are most suitable to manufacture PCM composite for industrial production, because it is economical and environmentally safe. The prepared form stable PCMs include $25 \%$ and $45 \%$ paraffin by mass fraction. According to the DSC results, the prepared composite PCMs retained their latent heat and phase change temperatures after 100 heating and cooling cycles. In addition to this the PCM composites were stable up to $155^{\circ} \mathrm{C}$. The FTIR results show that the prepared composites were a just physical combination of the paraffin wax and expanded perlite. The SEM images indicate that paraffin was uniformly dispersed into the EP and the composite maintains its form perfectly without any leakage and deformation after 100 heating and cooling cycles.

Based on the obtained results, it can be concluded that the presented form stable composite PCMs are suitable for use of thermal energy storage applications, especially for building energy reservation.

\section{REFERENCES}

1. Sharma, A., Tyagi, V.V., Chen, C.R., Buddhi, D. Review on Thermal Energy Storage with Phase Change Materials and Applications Renewable and Sustainable Energy Reviews 13 2009: pp. $318-345$.

2. Prakash, J., Garg, H.P., Datta, G. A Solar Heater with a Builtin Latent Heat Storage Energy Conversion and Management 25 1985: pp. $51-56$.

3. Rathod, M.K., Banerjee, J. Thermal Stability of Phase Change Materials Used in Latent Heat Energy Storage Systems: A review Renewable and Sustainable Energy Reviews 18 2013: pp. 246-258. https://doi.org/10.1016/j.rser.2012.10.022

4. Jamekhorshid, A., Sadrameli, S.M., Farid, M. A Review of Microencapsulation Methods of Phase Change Materials (Pcms) As a Thermal Energy Storage (TES) Medium Renewable and Sustainable Energy Reviews 31 2014: pp. 531-542. https://doi.org/10.1016/j.rser.2013.12.033

5. Kenisarin, M., Mahkamov, K. Solar Energy Storage Using Phase Changematerials Renewable and Sustainable Energy Reviews 11 2007: pp. 1913-965.

https://doi.org/10.1016/j.rser.2006.05.005

6. Zalba, B., Marin, J.M., Cabeza, L.F., Mehling, H. Review on Thermal Energy Storage With Phase Change: Materials, Heat Transfer Analysis and Applications Applied Thermal Engineering 23 2003: pp. 251-283.

7. Kenisarina, M.M., Kenisarina, K.M. Form-Stable Phase Change Materials for Thermal Energy Storage Renewable and Sustainable Energy Reviews 16 2012: pp. 1999-2040.

8. Xiangfa, Z., Hanning, X., Jian, F., Changrui, Z., Yonggang, J. Preparation and Thermal Properties of Paraffin/Porous Silica Ceramic Composite Composite Science and Technology 69 2009: pp. 1246-1249.

https://doi.org/10.1016/j.compscitech.2009.02.030

9. Feng, L., Zeng, J., Yang, H., Guo, Y., Li, W., Li, X. Preparation and Characterization of Polyethylene Glycol /Active Carbon Composites as Shape-Stabilized Phase Change Materials Solar Energy Matarials \& Solar Cells 95 2011: pp. 644-650. https://doi.org/10.1016/j.solmat.2010.09.033

10. Li, M., Wu, Z., Kao, H., Tan, J. Experimental Investigation of Preparation and Thermal Performances of Paraffin-Bentonite
Composite Phase Change Material Energy Conservation and Management 52 2011: pp. 3275-3281.

11. Wang, C., Feng, L., Zeng, J., Tian, W., Li, X. Shape-Stabilized Phase Change Materials Based on Polyethyleneglycol/ Porous Composite: Influence of Pore Structure of Carbon Materials Solar Energy Matarials \& Solar Cells 105 2012: pp. 21-26. https://doi.org/10.1016/j.solmat.2012.05.031

12. Cárdenas, B., León, N. High Temperature Latent Heat Thermal Energy Storage: Phase Change Materials, Design Considerations and Performance Enhancement Techniques Renewable and Sustainable Energy Reviews 27 2013: pp. 724-737. https://doi.org/10.1016/j.rser.2013.07.028

13. Zhang, Z., Zhang, N., Peng, J., Fang, X., Gao, X., Fang, Y. Preparation and Thermal Energy Storage Properties of Paraffin/Expanded Graphite Composite Phase Change Material Applied Energy 91 2012: pp. 426-431. https://doi.org/10.1016/j.apenergy.2011.10.014

14. Li, M., Wub, Z., Chena, M. Preparation and Properties of Gypsum-Based Heat Storage and Preservation Material Energy and Buildings 43 2011: pp. 2314-2319.

15. Yang, X., Yuan, Y., Zhang, N., Cao, X., Liu, C. Preparation And Properties of Myristic-Palmitic-Stearic Acid/Expanded Graphite Composites As Phase Change Materials For Energy Storage Solar Energy 99 2014: pp. 259-266. https://doi.org/10.1016/j.solener.2013.11.021

16. Sari, A., Karaipekli, A. Thermal Conductivities And Latent Heat Thermal Energy Storage Characteristics of Paraffin/Expanded Graphite Composite as Phase Change Material Applied Thermal Engineering 27 2007: pp. $1271-1277$.

17. Zhong, Y.J., Guo, Q.G., Li, S.Z., Shi, J.L., Liu, L. Heat Transfer Enhancement of Paraffin Wax Using Graphite Foam For Hermal Energy Storage Solar Energy Materials \& Solar Cells 94 2010: pp. $1011-1014$. https://doi.org/10.1016/j.solmat.2010.02.004

18. Zhang, D., Tian, S., Xiao, D. Experimental Study on The Phase Change Behavior of Phase Change Material Confined in Pores Solar Energy 81 2007: pp. 653-660.

19. Karaipekli, A., Sari, A. Capric-Myristic Acid/Expanded Perlite Composite As Form-Stable Phase Change Material For Latent Heat Thermal Energy Storage Renewable Energy 33 2008: pp. $2599-2605$. https://doi.org/10.1016/j.renene.2008.02.024

20. Lu, Z., Xu, B., Zhang, J., Zhu, Y., Sun, G., Li, Z. Preparation and Characterization of Expanded Perlite/Paraffin Composite As Form-Stable Phase Change Material Solar Energy 108 2014: pp. 460-466. https://doi.org/10.1016/j.solener.2014.08.008

21. Zhao, Y., Thapa, S., Weiss, L., Lvov, Y. Phase Change Heat Insulation Based on Wax-Clay Nanotube Composites Advanced Engineering Materials 16 2014: pp. 1391-1399. https://doi.org/10.1002/adem.201400094

22. Jiao, C., Ji, B., Fang, D. Preparation and Properties of LauricStearic Acid/Expanded Perlite Composite as Phase Change Materials for Thermal Energy Storage Material letters 67 2012: pp. 352-354.

23. Chen, Z., Shan, F., Cao, L., Fang, G. Preparation and Thermal Properties of N-Octadecane/Molecular Sieve Composites As Form-Stable Thermal Energy Storage Materials For Buildings Energy and Buildings 49 2012: pp. 423-428.

24. Mei, B., Zhang, R., Liu, Y., Zhang, J., Liu, E. Preparation of Capricacid/Halloysite Nanotube Composite as Form-Stable Phase Change Material for Thermal Energy Storage Solar Energy Materials \& Solar Cells 95 2011: pp. 2772-277. https://doi.org/10.1016/j.solmat.2011.05.024 